\title{
Interactions of ants with native and invasive lady beetles and the role of chemical cues in intraguild interference
}

\author{
Roman Bucher $^{1}\left[\right.$ - Laura M. Japke ${ }^{1,2} \cdot$ Ayse Gül Ünlü ${ }^{1,3} \cdot$ Florian Menzel $^{4}$
}

Received: 19 December 2019 / Accepted: 18 May 2021 / Published online: 24 May 2021

(c) The Author(s) 2021

\begin{abstract}
The predator-predator naïveté hypothesis suggests that non-native predators benefit from being unknown to native predators, resulting in reduced intraguild interference with native predators. This novelty advantage should depend on the ability of native predators to recognize cues of non-native predators. Here, we compared ant aggression and lady beetle reaction in four native and the invasive lady beetle species Harmonia axyridis. In addition, we tested whether lady beetle cuticular hydrocarbons (CHCs) are involved in species recognition, which might explain naïveté if the invasive species has a specific CHC profile. To this end, we conducted behavioral assays confronting two native ant species with both living lady beetles and lady beetle elytra bearing or lacking CHCs of different lady beetle species. Finally, we characterized CHC profiles of the lady beetles using GC-MS. In general, the aggression of Lasius niger was more frequent than that of Myrmica rubra and $L$. niger aggression was more frequent towards most native lady beetle species compared to $H$. axyridis. The removal of CHCs from lady beetle elytra reduced aggression of both ant species. If CHCs of respective lady beetle species were added on cue-free elytra, natural strength of $L$. niger aggression could be restored. CHC analyses revealed a distinct cue composition for each lady beetle species. Our experiments demonstrate that the presence of chemical cues on the surface of lady beetles contribute to the strength of ant aggression against lady beetles. Reduced aggression of L. niger towards $H$. axyridis and reduced avoidance behavior in $H$. axyridis compared to the equally voracious $C$. septempunctata might improve the invasive lady beetle's access to ant-tended aphids.
\end{abstract}

Keywords Biological invasion · Species interaction · Predator-predator naïveté · Ant aggression · Cuticular hydrocarbons · Harmonia axyridis $\cdot$ Coccinellidae $\cdot$ Formicidae

Communicated by Günther Raspotnig.

Roman Bucher

bucher@uni-marburg.de

1 Conservation Ecology, Philipps-Universität Marburg, Karl-von-Frisch-Str. 8, 35043 Marburg, Germany

2 Institute for Evolution and Biodiversity, Westfälische Wilhelms-Universität Münster, Hüfferstr. 1, 48149 Münster, Germany

3 Department of Ecology, Swedish University of Agricultural Sciences, Ulls väg 16, 75007 Uppsala, Sweden

4 Institute of Organismic and Molecular Evolution, Johannes Gutenberg-Universität Mainz, Hanns-Dieter-Hüsch-Weg 15, 55128 Mainz, Germany

\section{Introduction}

Non-native species invading areas beyond their native ranges are often a major threat to biodiversity (Lodge 1993; Mack et al. 2000; Bax et al. 2003) and their numbers are likely to increase due to worldwide traveling and transportation of goods (Lodge 1993; Hulme et al. 2008). Detrimental effects of invasive species on native species are well documented in the scientific literature, but we often lack a mechanistic understanding of the invasion success (Hayes and Barry 2008; Blackburn et al. 2011). A number of ecological and evolutionary hypotheses have been proposed aiming to explain the invasion success of non-native species (see Hufbauer and Torchin 2008), many of which focus on the role of biotic interactions. The 'enemy release hypothesis', for example, proposes that non-native species can benefit from missing predators (Keane and Crawley 2002; Colautti et al. 2004). Nevertheless, even if predators are present, the lack 
of shared evolutionary history between native prey and a non-native predator can facilitate the establishment of nonnative predators because of lacking predator recognition, also known as 'predator-prey naïveté hypothesis' (Cox and Lima 2006; Carthey and Banks 2014).

Predation risk is one of the great driving forces of prey populations (Lima and Dill 1990) and invasive predators, in particular, are causing rapid extinctions or declines in many native prey species (Mooney and Cleland 2001; Carthey and Banks 2014). Besides predator-prey systems, predator-predator interactions can contribute to invasion success as well. Killing of other predators (i.e. intraguild predation) or interference with other predators (i.e. intraguild interference) is common in food webs and can hamper top-down control of predators (Polis et al. 1989; Arim and Marquet 2004). Studies on the invasion success of non-native predators should thus consider intraguild interactions (Vance-Chalcraft and Soluk 2005). So far, the empirical evaluation of hypotheses aimed to explain invasion success is biased towards plants, vertebrates and aquatic organisms while terrestrial insects received relatively less attention (Parker et al. 1999; Bax et al. 2003) despite the fact that they represent a large part of the alien fauna (Kenis et al. 2009).

In insects, chemical cues play an important role in intraand interspecific communication (Howard and Blomquist 2005; Monnin 2006). Chemical recognition is best known in social insects, where cuticular hydrocarbons (CHCs) serve as intraspecific recognition cues (Greene and Gordon 2003; Howard and Blomquist 2005), but also as cues to recognize mutualists (Lang and Menzel 2011; Menzel and Schmitt 2012) or to avoid competitors or predators (Geiselhardt et al. 2011; Mestre et al. 2014; Wüst and Menzel 2017). The composition of substances and compounds of CHC profiles varies between species (Geiselhardt et al. 2011; Menzel et al. 2017). If species use such specific chemical cues for species recognition, they either need to learn or adapt to the chemical cues of their interaction partners (Sih et al. 2010). However, if species recognition is based on general cues (i.e. chemical substances present in many different species) they should be able to recognize non-native predators despite missing co-evolutionary history (Sih et al. 2010). Consequently, the similarity of chemical cues between native and non-native species as well as the species' ability to discriminate between different cue profiles is expected to influence interactions between native and non-native species and can thus contribute to the invasion success of non-native species (Sih et al. 2010).

Lady beetles have been intentionally redistributed across continents as pest control agents against aphids. In 1982, the multicolored Asian lady beetle, Harmonia axyridis, was introduced to Europe for the biological control of aphids in greenhouses and sold by biological control companies since 1995 (Brown et al. 2007). In 2002, first feral populations were sighted in the Netherlands, Belgium and Germany (Babendreier 2007). Since then, H. axyridis has spread over Central Europe and is now a dominant member of the lady beetle community in many European countries. $H$. axyridis displaces native lady beetles in Europe but also in North America (Elliott et al. 1996; Koch 2003; Brown et al. 2011; Roy et al. 2012). The rapid decline in the abundance of native lady beetle species in the last 30 years has become an increasing cause for concern (Alyokhin and Sewell 2004; Harmon et al. 2006).

So far, research on ecological effects of invasive lady beetles on native communities has concentrated on intraguild predation among lady beetles, on prey depletion, on body size and fecundity, on phenology as well as on habitat displacement (reviewed in Roy and Wajnberg 2008). More recently, the role of chemical protection (Kajita et al. 2010, 2014) and endoparasites (Vilcinskas et al. 2013) of invasive lady beetles for the invasion success has also been studied. In addition, differences in ant aggression towards native and non-native lady beetles could contribute to the invasion success of non-native lady beetles as well (Finlayson et al. 2009). Ants are known as predators, ecosystem engineers and for their important role in communities as hemipteran mutualists (Flatt and Weisser 2000; Stadler and Dixon 2005). Some ant species show aphid tending behavior: they feed on honeydew and defend aphids against various predators (Way 1963; Völkl et al. 1999; Stadler and Dixon 2005). Relying on aphids as a food source, lady beetles are competitors of ants and are thus particularly prone to ant aggression. Reduced intraguild interference with ants is expected to contribute to the invasion success of non-native lady beetles because of enhanced food access. So far, we lack the understanding to which extent ant aggression contributes to the invasion success of $H$. axyridis in Europe (Pell et al. 2008).

Here, we compared ant aggression towards lady beetles and lady beetle reaction upon contact with ants between native and non-native lady beetles in Europe. In our laboratory experiments, we confronted individuals of four native lady beetle species (Hippodamia variegata, Adalia bipunctata, Propylea quatuordecimpunctata, and Coccinella septempunctata) and the invasive lady beetle species $H$. axyridis with individuals of two co-occurring native ant species (Lasius niger and Myrmica rubra). In an additional experiment, we confronted ants with chemically manipulated lady beetle elytra. The elytra were either untreated, washed and thus expected to be free of chemical cues, or treated with chemical cues of the different lady beetle species. This dummy experiment allowed us to evaluate the role of chemical cues for ant aggression. Finally, we analyzed the chemical composition of CHCs using gas chromatographymass spectrometry (GC-MS) to compare the similarity of chemical cues among the lady beetle species used in our behavioral assays. We expected (1) more ant aggression 
towards native lady beetles compared to invasive lady beetles; (2) more reactions of native lady beetles compared to invasive lady beetles if confronted with native ants. In our dummy experiment, we expected (3) fewer ant aggression towards washed elytra compared to untreated elytra and (4) comparable ant aggression between elytra with artificially applied lady beetle cues and untreated elytra. Regarding the chemical composition of lady beetle cues, we expected (5) a species-specific CHC profile for each lady beetle species included in our experiments.

\section{Methods}

\section{Study species}

Adult individuals of the five lady beetle species were collected from field margins in the agricultural landscape of Central Europe (Germany, France and Switzerland) from March till September 2017. Additional individuals of $A$. bipunctata were purchased (Bioinsecte, Adavalue SPRL, Othée, Belgium) as we could not find enough individuals in the wild. Lady beetle body size (from the end of the abdomen up to the front of the head) was measured under a binocular and lady beetles were weighted with a precision balance (H. axyridis: $5.24 \pm 0.12 \mathrm{~mm}, 0.024 \pm 0.001 \mathrm{~g} ; H$. variegata: $2.77 \pm 0.07 \mathrm{~mm}, 0.009 \pm 0.000 \mathrm{~g} ;$ A. bipunctata: $3.32 \pm 0.08 \mathrm{~mm}, 0.013 \pm 0.000 \mathrm{~g} ;$ P. quatuordecimpunctata: $3.17 \pm 0.07 \mathrm{~mm}, 0.010 \pm 0.000 \mathrm{~g} ;$ C. septempunctata: $5.29 \pm 0.13 \mathrm{~mm}, 0.041 \pm 0.001 \mathrm{~g})$. Small groups of lady beetles separated by species were kept in Petri dishes $(\varnothing$ $9 \mathrm{~cm}$ ) with moistened cotton and stored in a climate cabinet (MLR-352H, Panasonic Corporation, Kadoma, Osaka, Japan; at $20{ }^{\circ} \mathrm{C}, 65 \% \mathrm{RH}, 16 / 8 \mathrm{~h}$ day-night rhythm). The lady beetles were fed ad libitum with pea aphids Acyrthosiphon pisum. An initial population of aphids was provided by the Julius-Kühn-Institut (Braunschweig, Germany). Aphids were reared on bean plants Vicia faba (variety Sutton Dwarf; Kings Seeds, Essex, UK). Plants had to be renewed twice a week. Both aphids and plants were kept in climate cabinets $\left(20{ }^{\circ} \mathrm{C}, 65 \% \mathrm{RH}, 16 / 8 \mathrm{~h}\right.$ day night rhythm).

Ant colonies of Lasius niger and Myrmica rubra were excavated in meadows and at forest edges in the vicinity of Marburg, Germany. Typical L. niger colonies consist on average of 14000 ant workers, M. rubra colonies typically consist of 1010 ant workers in average (Seifert 2007). All lady beetle species co-occurred at the sites where ants were collected, with $H$. axyridis being the most abundant lady beetle species during the study period and $H$. variegata and A. bipunctata being relatively rare at these sites. We always kept two ant colonies per species with brood during the whole study period. They were replaced by fresh colonies for the experiment with lady beetle elytra because only a few active workers and/or no brood were present anymore. In total, we ended up with 8 ant colonies for both experiments. Each colony was kept in a terrarium $(20 \mathrm{~cm} \times 20 \mathrm{~cm} \times 30 \mathrm{~cm})$ in the laboratory. The upper edge of the terraria were covered with Fluon ${ }^{\circledR}$ (Polytetrafluoroethylene dispersion) to prevent the ants from escaping. Water was provided in tubes clogged with cotton and the soil was moistened with a spray bottle twice a week. Ants were fed twice a week with honey and with dead house crickets Acheta domesticus.

\section{Aggression experiments with living lady beetles}

The behavioral assays were performed in Petri dishes ( $\varnothing$ $9 \mathrm{~cm}$ ) with Fluon ${ }^{\circledR}$-covered walls to prevent the ants from escaping. Each Petri dish was only used once to prevent contamination with ant or lady beetle cues. For each trial, three ant workers were caught out of one colony and placed in the Petri dish. After an acclimatization time of $15 \mathrm{~min}$, one adult lady beetle of the respective species was placed in the center of the Petri dish. During three minutes the following elements of ant behavior were quantified: avoidance of lady beetles, prolonged antennation, opening mandibles, chasing, grasping, biting, and stinging (see Finlayson et al. 2009). To compare the aggression strength of native ants against native and non-native lady beetles, we compared counts of strong aggressive behaviors that involved direct contact with lady beetles or that are associated with behavioral reactions in lady beetles (chasing, grasping, biting and stinging). Two alternative approaches, i.e. the aggression index proposed by Finlayson et al. (2009), and an analysis of the proportion of strong aggressive behaviors, are included in the supplementary material (S2) for comparison. In addition, the following elements of lady beetle behavior were quantified: continuing behavior, changing movement direction while walking, retracting legs or antennae, preening, turning on back, flailing legs, fluttering wings, backing, running away and flying away (see Finlayson et al. 2009). Here, behavioral elements leading to energetically costly increase in movement such as turning on back, flailing legs, fluttering wings, backing, running away and flying away were considered as strong reaction and are the basis of the analyses. As for ant aggression, we included two alternative analytical approaches of lady beetle reaction in the supplementary material (S2) for comparison. If behavioral elements continued for more than three seconds they were counted again to account for the duration (see e.g. Menzel et al. 2009). The frequencies of each behavioral element observed in our experiments are provided as supplementary material (S1) All behavioral assays were recorded with a video camera (LUMIX DMC-FZ300, Panasonic Corporation, Kadoma, Osaka, Japan) mounted on a tripod. The recordings were used for a slow-motion replay if many different behavioral elements occurred very quickly. For the aggression experiments with 
living lady beetle individuals, we compared five lady beetle species in combination with two ant species with at least 20 replicates per combination, resulting in 206 replicates. The order of lady beetles species identity during the experimental period was randomized.

To compare the frequency of ant aggression and lady beetle reaction between the ant and lady beetle species, we compared the counts of strong interactions (i.e. the sum of observed strong aggressive behaviors and the sum of strong reactions; see above). First, we calculated a generalized linear mixed model (GLMM) with ant and lady beetle species identity as well as the interaction between both fixed effects. The model assumed a Poisson error distribution and included ant colony identity as a random effect. In addition, we included an observation-level random effect to account for overdispersion (Harrison 2014). Since behavioral interactions differed between ant species, differences in interaction strength between the lady beetle species were analyzed for each ant species separately. In case of significant overall effects based on a subsequent $\chi^{2}$-test, a Tukey post-hoc test was applied to obtain pairwise contrasts between the lady beetle species with adjusted p-values (to account for multiple comparisons). All statistical analyses were conducted using $\mathrm{R}$ version 3.5.2 (R Development Core Team 2018).

\section{Aggression experiments with manipulated elytra}

We used lady beetle elytra as dummies to manipulate CHCs. Elytra can easily be removed from dead beetles. They contain no secretory glands (Pettersson 2012), and our analyses did not detect any other compounds than $\mathrm{CHCs}$ in elytra extracts. Ants can grasp and bite easily into these strongly sclerotized body parts. A number of 60 adult individuals per lady beetle species plus additional $200 \mathrm{H}$. axyridis individuals were killed in the freezer at approximately $-10{ }^{\circ} \mathrm{C}$ for $12 \mathrm{~h}$. Thereafter, the dead lady beetles were defrosted and both elytra were broken off with a clean tweezer. The resulting 120 elytra per lady beetle species were divided into 80 elytra for the cue extraction and 40 elytra remained untreated. To obtain cue-free lady beetle elytra, $400 \mathrm{H}$. axyridis elytra were repeatedly immersed in clean $20 \mathrm{ml}$ hexane or dichloromethane (i.e. to solve apolar and polar organic substances): hexane for ten min, dichloromethane for one hour, hexane for one hour, dichloromethane for ten min and again hexane for ten min. Between each step, the elytra were dried on clean paper towel for $30 \mathrm{~s}$. Half of these cue-free elytra were later used as negative treatments (i.e. cues washed away) and the other half as positive treatment (i.e. adding lady beetle cues of the respective species). To obtain the cues of the different lady beetle species, 80 elytra of each lady beetle species were covered with $4.0 \mathrm{ml}$ hexane for ten minutes. Afterwards, the solutions were transferred into smaller vials $(4.0 \mathrm{ml}, 15 \mathrm{~mm} \times 45 \mathrm{~mm})$ and were stored without cover to allow the hexane to evaporate. The $\mathrm{CHCs}$ were then resolved in $800 \mu \mathrm{l}$ hexane.

In each aggression trial, three ants were confronted with one elytron of either of the following treatments: untreated elytron of the respective lady beetle species, cue-free elytron of $H$. axyridis with pure hexane (negative treatment), or cuefree elytron of $H$. axyridis with added cues of the respective lady beetle species solved in hexane (positive treatment). To this end, the elytron was held with a spring steel tweezer and $10.0 \mu 1$ hexane was applied on the outer surface with a micropipette. After the hexane had dried, the elytron was turned and another $10.0 \mu \mathrm{l}$ hexane was applied to the inner surface. For the positive treatment, the same procedure was applied but with the cue solution of the respective lady beetle species instead of pure hexane. In this dummy experiment, we ended up with 200 replicates with untreated elytra (20 replicates per lady beetle and ant species combination), 200 replicates of the negative treatment and 200 replicates of the positive treatment (with 20 replicates per cue-donator lady beetle and ant species combination) resulting in a total of 600 replicates. During the behavioral assays, ant aggression was quantified as described above. Counts of strong ant aggression were analyzed using a GLMM with Poisson error distribution. Treatment, ant species, and lady beetle species, as well as their interactions, entered the model as fixed effects with ant colony identity and observation-level as random effects (see analysis of the experiment with living lady beetles). Differences in ant aggression between the treatments were compared for each ant species separately. A Tukey post-hoc test was applied to obtain pairwise contrasts between the treatments.

\section{Chemical analysis}

CHC extracts for chemical analyses were obtained by immersing the two elytra of one freeze-killed lady beetle in $1.0 \mathrm{ml}$ hexane for ten minutes. This was done for nine $H$. axyridis, eight $H$. variegata, four $A$. bipunctata, five $P$. quatuordecimpunctata, and seven $C$. septempunctata individuals. All extracts were concentrated under nitrogen flow and injected into a 7890A gas chromatograph coupled to a 5975C mass spectrometer (both Agilent Technologies Inc., Santa Clara, USA) in the split less mode at $250{ }^{\circ} \mathrm{C}$. Helium was used as carrier gas $(1.2 \mathrm{ml} / \mathrm{min})$. The stationary phase was a capillary column (Phenomenex Zebron ZB5-HT Inferno, $30 \mathrm{~m} \times 0.25 \mu \mathrm{m} \times 0.25 \mu \mathrm{m}$ ). Oven temperature was $60^{\circ} \mathrm{C}$ for two min, then increased to $200{ }^{\circ} \mathrm{C}$ by $60{ }^{\circ} \mathrm{C} / \mathrm{min}$, and then increased to $320^{\circ} \mathrm{C}$ by $4{ }^{\circ} \mathrm{C} / \mathrm{min}$, where it remained constant for ten minutes. We used an ionization current of $70 \mathrm{eV}$ and scanned molecular fragments from 40 to $650 \mathrm{~m} / z$. Data were acquired using the software MSD Chem Station E.02.02 (Agilent Technologies). We analyzed all hydrocarbons with a chain 
length $>\mathrm{C} 20$ and an average abundance of at least $0.5 \%$; the abundance of all hydrocarbons $<\mathrm{C} 20$ totaled less than one percent of the total. Substances were identified based on retention time and diagnostic ions. Chemical differences between species were tested with a PERMANOVA (999 permutations, command adonis, R-package vegan, Oksanen et al. 2013) based on Bray-Curtis distances, which contained the relative abundances of all hydrocarbons as a dependent variable in a multivariate analysis.

(a) Lasius niger

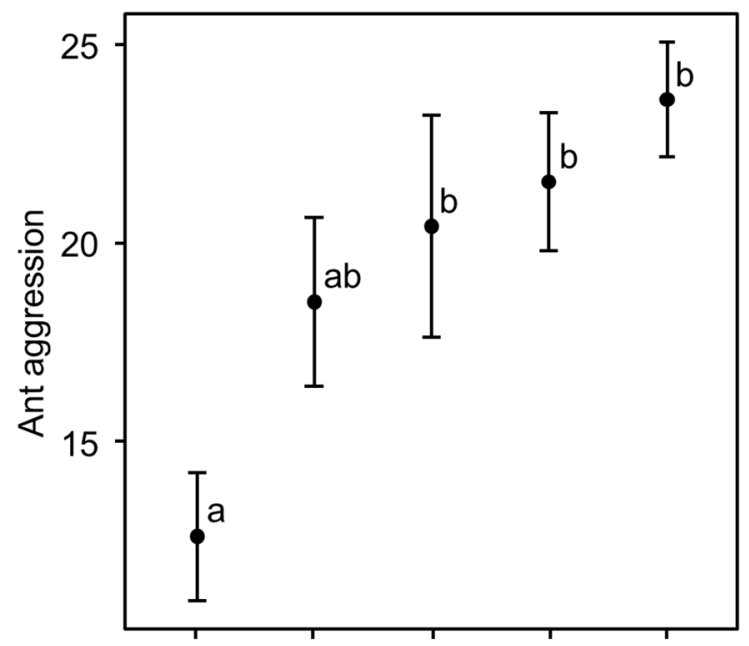

(c)

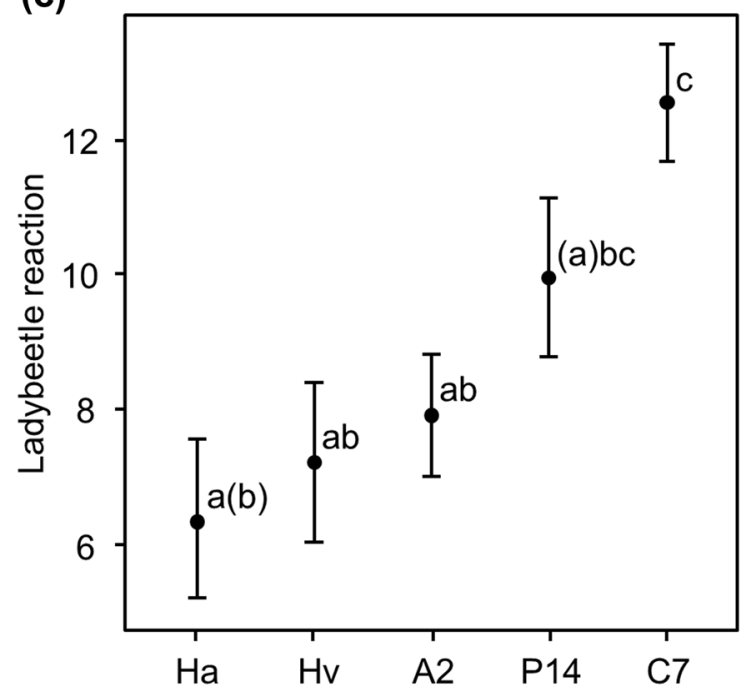

Fig. 1 Frequency of strong aggression of a $L$. niger and $\mathbf{b}$ M. rubra towards the studied lady beetle species (Ha H. axyridis, $H v$ H. variegata, A2 A. bipunctata, P14 P. quatuordecimpunctata, C7 C. septempunctata) and frequency of strong reaction of the five lady beetle

\section{Results}

\section{Ant aggression towards living lady beetles}

The frequency of ant aggression towards lady beetles differed between lady beetle species $\left(\chi_{4,194}^{2}=22.85, p<0.001\right)$ and the frequency of $L$. niger aggression was higher than that of $M$. rubra $\left(\chi_{1,194}^{2}=64.41, p<0.001\right)$. We found no interactive effect of lady beetle and ant species identity on ant aggression frequency $\left(\chi_{4,194}^{2}=3.94, p=0.41\right)$. For $L$. niger, the frequency of aggression differed between lady beetle species (Fig. $1 \mathrm{a} ; \chi^{2}{ }_{4,96}=21.32, p<0.001$ ). Here, the
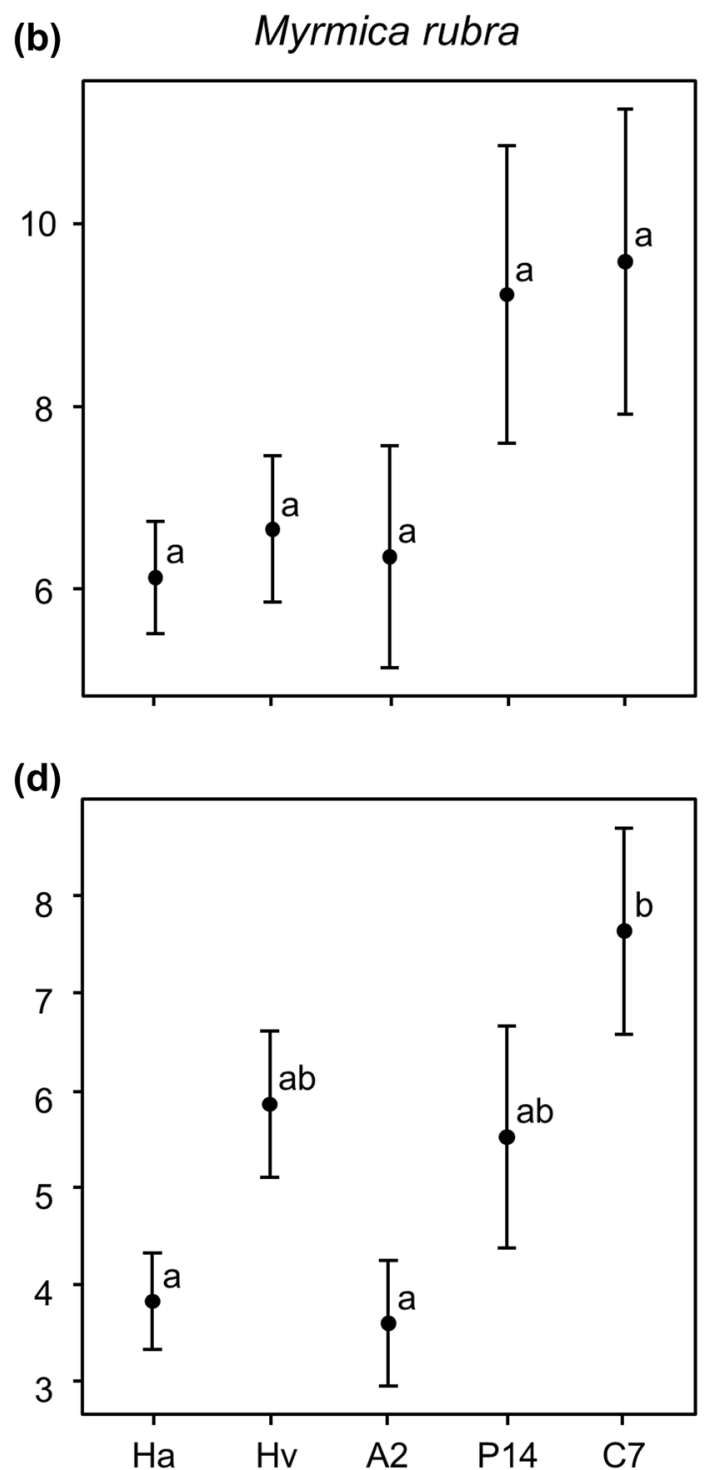

species upon encountering c $L$. niger and d $M$. rubra (mean $\pm \mathrm{SE})$. Different lowercase letters indicate statistical differences $(\alpha<0.05)$. Letters in brackets indicate statistical trends $(\alpha<0.1)$. Note that $\mathrm{y}$-axes are on different scales 
frequency of ant aggression was higher towards $C$. septempunctata $(z=4.33, p<0.001), P$. quatuordecimpunctata $(z=3.69, p=0.002)$, and A. bipunctata $(z=2.85, p=0.04)$ compared to $H$. axyridis. For $M$. rubra, the frequency of ant aggression did not differ between lady beetle species (Fig. $1 b ; \chi_{4,100}^{2}=7.07, p=0.13$ ).

\section{Reaction of lady beetles to ant encounters}

The frequency of lady beetle reactions upon contact with ants differed between lady beetle species $\left(\chi_{4,194}^{2}=31.54\right.$, $p<0.001)$ and the frequency of lady beetle reactions upon contact with $L$. niger was higher compared to that after confrontations with $M$. rubra $\left(\chi_{1,194}^{2}=32.81, p<0.001\right)$. We found no interactive effect of lady beetle and ant species identity on the frequency of lady beetle reaction $\left(\chi_{4,194}^{2}=5.37, p=0.25\right)$. Upon contact with L. niger, the frequency of lady beetle reactions differed between lady beetle species (Fig. $1 \mathrm{c} ; \chi_{4,96}^{2}=21.67, p<0.001$ ). Here, $C$. septempunctata showed more reactions confronted with $L$. niger compared to $H$. axyridis $(z=4.09, p<0.001), H$. variegata $(z=3.46, p=0.005)$ and A. bipunctata $(z=2.76, p=0.05)$. In addition, the frequency of reactions tended to be higher in $P$. quatuordecimpunctata compared to $H$. axyridis $(z=2.59$, $p=0.07)$. For encounters with $M$. rubra, the frequency of lady beetle reactions also differed between lady beetle species (Fig. 1d; $\chi_{4,100}^{2}=15.34, p=0.004$ ). Here, lady beetle reaction was more frequent in $C$. septempunctata compared to H. axyridis $(z=3.10, p=0.02)$ and A. bipunctata $(z=3.31$, $p=0.01$ ). We found no further pairwise differences in the frequency of lady beetle reactions upon contact with $M$. rubra among the remaining lady beetle species.

\section{Aggression towards lady beetle CHCs}

The frequency of ant aggression differed between the CHC treatments (Fig. $2 ; \chi_{2,572}^{2}=63.88, p<0.001$ ) but not between the two ant species $\left(\chi^{2}{ }_{1,572}=1.95, p=0.16\right)$ or between the different lady beetle species $\left(\chi_{4,572}^{2}=3.00, p=0.56\right)$. We found a significant ant species/lady beetle species interaction $\left(\chi_{4,572}^{2}=11.64, p=0.02\right.$; see supplementary material $\mathrm{S} 2$ for species-wise analyses). The treatment/ant species interaction $\left(\chi_{2,572}^{2}=3.70, p=0.16\right)$, the treatment/lady beetle species interaction $\left(\chi_{8.572}^{2}=13.34, p=0.10\right)$, and the three-way interaction $\left(\chi_{8,572}^{2}=4.96, p=0.76\right)$ were not significant. For $L$. niger, the frequency of ant aggression differed between the CHC treatments (Fig. $2 ; \chi^{2}{ }_{2,289}=50.68 . p<0.001$ ) but not between lady beetle species $\left(\chi_{4,289}^{2}=6.84, p=0.14\right)$. We did not find a significant treatment/lady beetle species interaction $\left(\chi_{8,289}^{2}=8.45, p=0.39\right)$. Here, we found fewer ant aggression when chemical cues were removed compared to untreated elytra $(z=6.74, p<0.001)$. The application of lady beetle cues of the respective species on cue-free $H$.

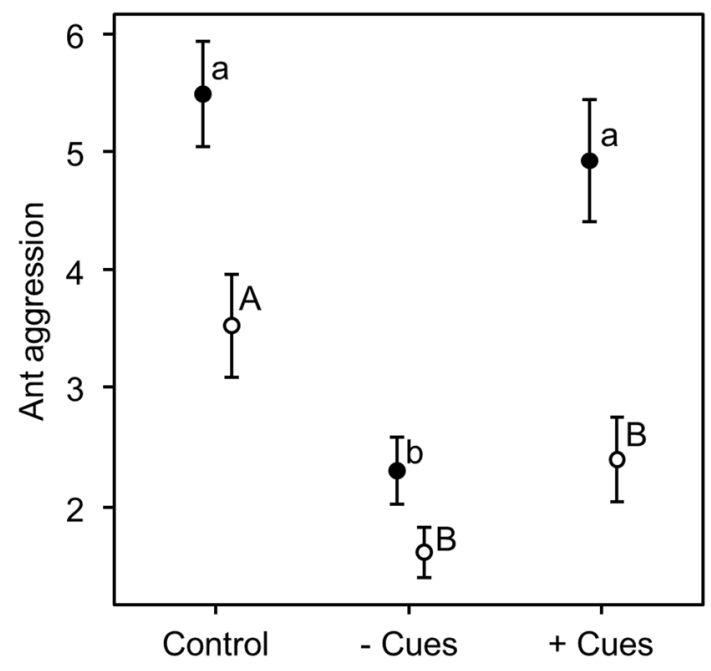

Fig. 2 Frequency of strong aggression (mean $\pm \mathrm{SE}$ ) of L. niger (black) and $M$. rubra (white) towards untreated elytra of the studied lady beetle species (Control), cue-free $H$. axyridis elytra (-Cues), and initially cue-free $H$. axyridis elytra bearing the cues of the respective lady beetle species (+Cues). Different letters indicate statistical differences $(\alpha<0.05)$

axyridis elytra increased the frequency of ant aggression $(z=5.22, p<0.001)$ and was similar to the aggression against untreated elytra $(z=1.65, p=0.23)$. The frequency of aggression by $M$. rubra differed between CHC treatments (Fig. $2 ; \chi_{2,285}^{2}=20.29, p<0.001$ ) and tended to differ between lady beetle species $\left(\chi_{4,285}^{2}=8.15, p=0.09\right)$. We did not find a significant treatment/lady beetle species identity interaction $\left(\chi_{8,285}^{2}=9.83, p=0.28\right)$. Here, the frequency of ant aggression was reduced when chemical cues were removed compared to untreated elytra $(z=4.57, p<0.001)$. The application of lady beetle cues of the respective species on cue-free elytra did not restore aggression compared to cue-free $H$. axyridis elytra $(z=1.83, p=0.16)$. Consequently, the frequency of ant aggression towards elytra treated with lady beetle cues was lower compared to untreated elytra $(z=2.77, p=0.02)$. Treatment comparisons separated by lady beetle species are provided as supplementary material (S2).

\section{Chemical composition of cues}

The composition of the chemical cues differed between lady beetle species (pseudo- $F_{4,28}=58.57, p<0.001$ ) revealing a distinct species-specific chemical profile for each lady beetle species (see Figs. 3 and 4; all pairwise-comparisons: pseudo- $F \geq 41.7, p \leq 0.05$ ). Here, cue composition was relatively similar between $H$. axyridis and $H$. variegata (multivariate distance between species centroids based on Bray-Curtis distances: 0.54). The profiles of both species were characterized by a very 
Coccinella septempunctata

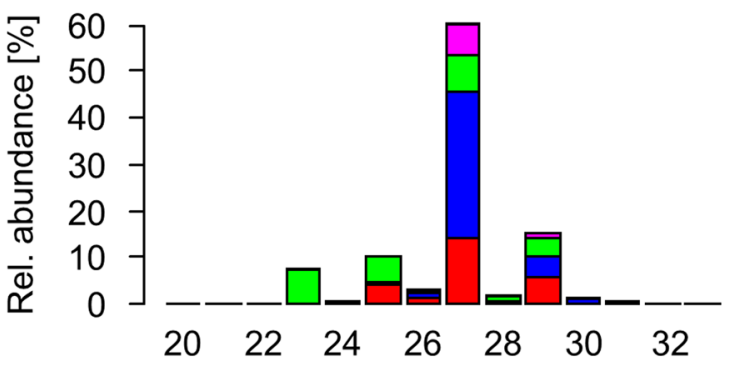

Propylea quatuordecimpunctata

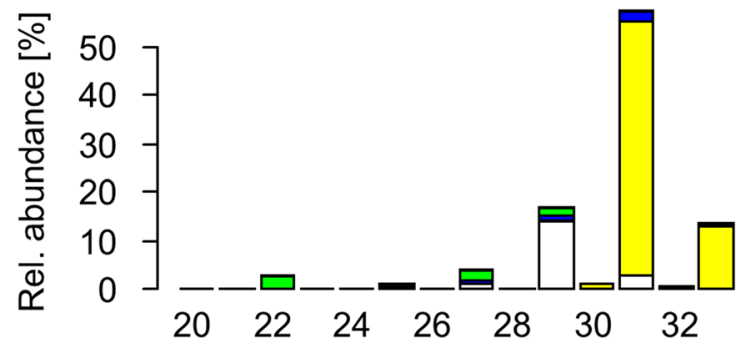

Harmonia axyridis

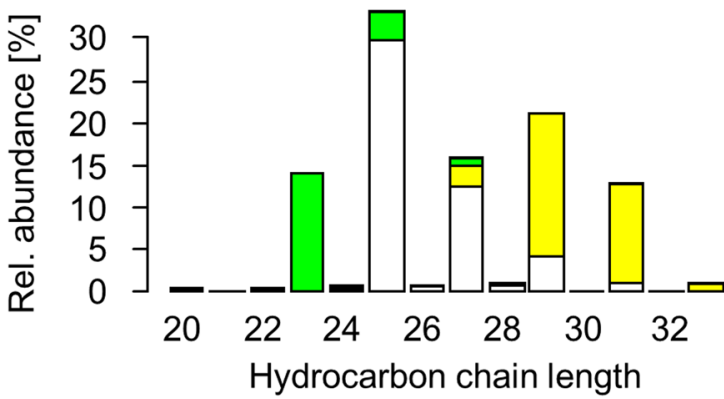

Fig. 3 Schematic cuticular hydrocarbon (CHC) profile of the lady beetle species included in the behavioral assays. The bars represent the relative abundances of different substance classes at different

high proportion of alkenes, followed by alkadienes and $n$-alkanes. In contrast, the profile of P. quatuordecimpunctata was dominated by alkadienes (distance to the $H$. axyridis centroid: 0.73), while the profiles of C. septempunctata and A. bipunctata strongly differed from all previous species, having high proportions of monomethyl alkanes (as well as di- and trimethyl alkanes in the case of $C$. septempunctata) (distance to the $H$. axyridis centroid for both species: 0.86). Identified substances and chromatograms of each lady beetle species are provided as supplementary material (S1).
Adalia bipunctata

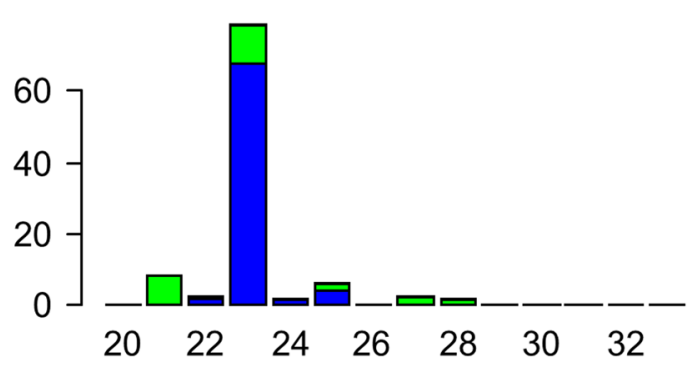

Hippodamia variegata
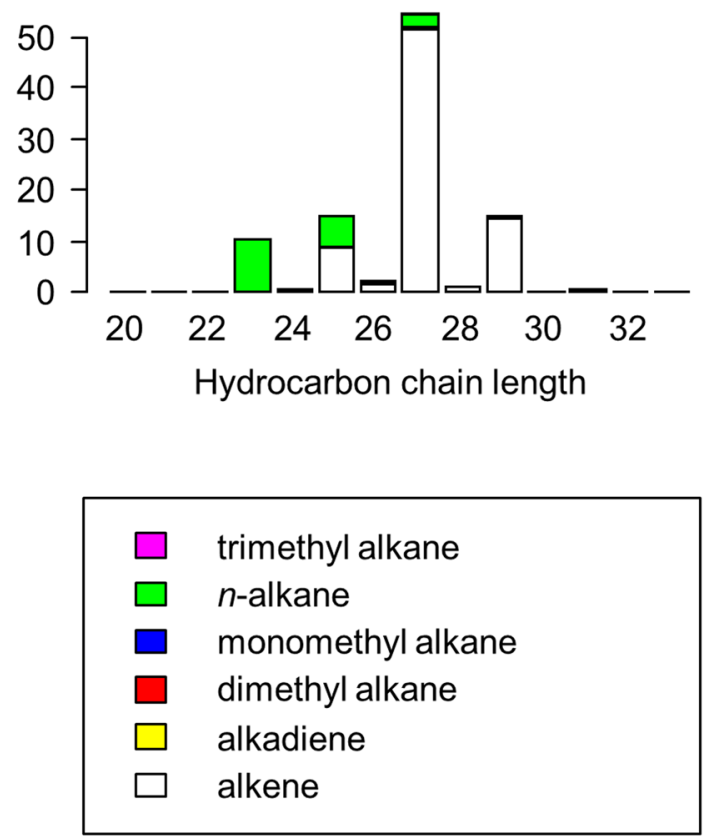

chain lengths. Note that this representation does not show differences between hydrocarbons of the same hydrocarbon class and chain length

\section{Discussion}

Our behavioral experiments revealed that ant aggression as well as lady beetle reaction differed between ant and lady beetle species. Across lady beetle species, strong aggressive interactions were more often observed in $L$. niger than in $M$. rubra. In particular, the aggression of L. niger was more frequent against most native lady beetle species compared to the invasive $H$. axyridis. Additionally, $C$. septempunctata showed more reactions upon encountering both 


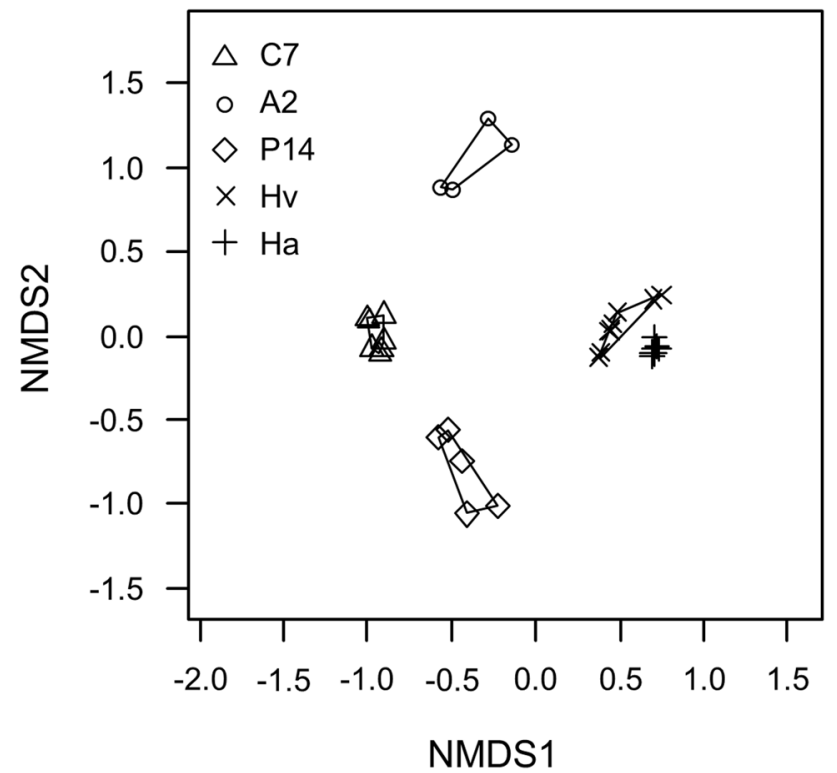

Fig. 4 Ordination plot (Non-metric MultiDimensional Scaling with Bray-Curtis dissimilarity) based on the relative abundance of identified substances. Each symbol represents a lady beetle individual of the respective species ( $\mathrm{Ha} \mathrm{H}$. axyridis, $\mathrm{Hv} \mathrm{H}$. variegata, A2 A. bipunctata, P14 P. quatuordecimpunctata, C7 C. septempunctata)

ant species compared to $H$. axyridis. Removing chemical cues from lady beetle elytra reduced aggression of both ant species and the addition of lady beetle cues on cue-free elytra increased the frequency of $L$. niger aggression but not that of M. rubra. Our chemical analyses showed a distinct species-specific CHC profile for each lady beetle species, which is a prerequisite for predator-predator naïveté.

\section{Ant aggression and lady beetle reaction}

The most evident pattern we observed was the higher frequency of strong $L$. niger aggression compared to that of $M$. rubra. L. niger is known to be more aggressive than $M$. rubra and often dominates $M$. rubra in direct encounters (Binz et al. 2014). In addition, ants of the genus Lasius are more strongly involved in trophobiosis with aphids and even overwinter aphids in their nests whereas ants of the genus Myrmica regularly prey on other arthropods including aphids (Seifert 2007). Consequently, L. niger is expected to be a stronger lady beetle competitor compared to M. rubra.

Less frequent $L$. niger aggression (fewer grasping and biting) against $H$. axyridis compared to most native lady beetle species tested-except for $H$. variegata-is in line with our expectation. These results suggest that $L$. niger lack the ability to recognize non-native $H$. axyridis and to react accordingly. Furthermore, $H$. axyridis is an equally voracious aphid predator compared to $C$. septempunctata (Ünlü et al. 2020; Bertleff et al. 2021) and consequently an equally strong competitor. Thus, one would expect a selection pressure towards ants to become equally aggressive to $H$. axyridis in the long term. If recognition is learned, $H$. axyridis should elicit strong aggression, since it was by far the most common lady beetle at the sites of ant collection and some ant workers used in our study might have encountered it before. However, the ants were much less aggressive towards this species. So far, it is largely unknown whether ant responses to different insect species are innate or learnt. Several studies reported that ants can be conditioned to certain insect odors (Bos et al. 2012; Dupuy et al. 2006), suggesting that at least some responses can be learned. However, it is equally possible that there are default innate responses to certain cues, a scenario which would pose a benefit for invasive species if they differ in cues. Further experiments with completely lady beetle-naïve ants would be required to test whether the recognition ability is learned or innate.

Regarding the role of intraguild interactions in the antlady beetle-aphid system, the vast majority of studies focuses on intraguild predation between lady beetles (reviewed by Pell et al. 2008), whereas information about differences in ant aggression against lady beetles is scarce. To our knowledge, the only multispecies comparison including native and non-native lady beetle species has been conducted by Finlayson et al. (2009). In their study aggression of M. rubra workers tending potato aphids Macrosiphum euphorbiae was compared between North American, European, and the Asian lady beetle species $H$. axyridis. Similar to our results, Finlayson et al. (2009) found no differences in the intensity of $M$. rubra aggression against novel $H$. axyridis and co-evolved $C$. septempunctata. Lacking lady beetle species discrimination in M. rubra but not in L. niger might again be explained by their involvement in trophobiosis with aphids (i.e. more competitive encounters with lady beetles), which is more pronounced in the genus Lasius than in the genus Myrmica (Seifert 2007).

The reaction of the different lady beetle species towards ants mirrored to some extent differences in the frequency of ant aggression among the lady beetle species, i.e. more aggressive interactions led to more escape behavior. In particular, C. septempunctata showed twice as many strong reactions if confronted with both ant species compared to $H$. axyridis. Although $L$. niger aggressions were more frequent against $C$. septempunctata, more frequent reactions suggest that $C$. septempunctata is able to effectively avoid ant aggression. Earlier studies under more natural conditions indicate that $C$. septempunctata is quite successful in avoiding ants (Sloggett et al. 1998) and is better protected with alkaloids compared to A. bipunctata (Marples 1993). Not only H. axyridis but also A. bipunctata showed fewer reactions upon contact with $M$. rubra compared to C. septempunctata. This pattern is in contrast with our hypothesis and suggest species-specific 
responses among lady beetle species (e.g. depending on body size-related competition for aphids or other exclusion mechanisms exist under more natural conditions). In summary, our laboratory experiments revealed more frequent aggression of $L$. niger compared to $M$. rubra and provide evidence that $L$. niger aggression as well as lady beetle reaction less frequent in the invasive $H$. axyridis compared to the equally voracious native lady beetle $C$. septempunctata - with potential implications for their invasion success in Europe.

\section{Implications of ant aggression for the invasion success of $\boldsymbol{H}$. axyridis}

Ants have pervasive and complex effects on terrestrial ecosystems by influencing community structure but also by hampering top-down control via consumptive and non-consumptive effects (Stadler and Dixon 2005; Sanders et al. 2011; Mestre et al. 2014; Penn and Athey 2020). For example, the presence of North American ants reduced soybean aphid predation by Orius insidiosus (Hemiptera: Anthocoridae) and $H$. axyridis and led to a tenfold increase in aphid numbers (Herbert and Horn 2008). As a result of ant aggression, lady beetles only feed on ant-tended aphids when untended prey is scarce (Sloggett and Majerus 2000). In the presence of L. niger, reduced ant aggression-possibly due to predator-predator naiveté-may reinforce the competitive advantage of the invasive $H$. axyridis over $C$. septempunctata. However, experiments under more natural conditions would be necessary to infer competitive advantages of invasive lady beetles due to release form intraguild interference by ants. Differences in ant aggression between different lady beetle species could change if ants are actually tending aphids (Way 1963) and lady beetle species could differ in their foraging preference. For example, the myrmecophilous Coccinella magnifica received similar ant aggression compared to $C$. septempunctata on trails but only C. magnifica fed upon tended aphids (Sloggett et al. 1998). Given the strong context dependency in ant-lady beetle interactions, we see the need for more natural experiments including ants, lady beetles, and aphids to compare differences in aphid predation rates among lady beetle species in the presence and absence of ants. Such experiments would ideally include different lifestages of lady beetles as well as different competing lady beetle species. Nonetheless, the experimental approach presented here is very well suited to study behavioral responses to native and non-native lady beetle species since they allow large replicate numbers across multiple species and enable detailed behavioral analyses (e.g. to disentangle chemical and behavioral cues underlying aggression in ants, see Foitzik et al. 2007; Steiner et al. 2007; Menzel et al. 2009).
The role of chemical cues for intraguild interference with ants

Ants were aggressive against lady beetle elytra, albeit less so than against living beetles. Removal of chemical cues led to a strong reduction of ant aggression. This indicates that chemical cues are highly relevant for intraguild interactions between lady beetles and ants. This is not surprising, given that for ants, cuticular chemical cues, such as cuticular hydrocarbons, are the basis for the recognition of nestmates (Howard and Blomquist 2005) and mutualistic interaction partners (Lang and Menzel 2011; Menzel and Schmitt 2012). The addition of lady beetle cues on initially cue-free elytra led to similar L. niger aggression compared to the untreated elytra demonstrating that chemical cues elicit aggression of $L$. niger. Surprisingly, the addition of lady beetle cues did not increase the frequency of aggression by $M$. rubra. The aggression of $M$. rubra was generally less frequent than that of $L$. niger, which might be due to differences in their food preference (see discussion above). The chemical treatment might further weaken behavioral responses because the cues are not presented in the entirely natural form, and hence trigger weaker responses. In addition, the lady beetle extract might have contained defense secretions, which might have remained undetected in our chemical analyses (e.g. coccinelline). Such compounds might have deterred ants to some extent and thus weakened ant aggression. However, it seems unlikely that it affected M. rubra but not L. niger. At least for L. niger, aggression could be restored by re-application of $\mathrm{CHC}$ extracts reconfirming their role for species recognition. However, in contrast to the live beetles, ant aggression did not differ between the untreated elytra of the respective lady beetle species (see Supplementary Material S2, Fig. S2e). Hence, the CHCs alone might not fully explain differences in ant aggression, suggesting that behavioral responses by the lady beetles further modulate ant aggression. Finlayson et al. (2009) observed that ant aggression was higher if some lady beetle species had more exposed body parts on which ants could grasp. Albeit CHCs play an important role in species recognition, analyses of lady beetle CHCs targeted at sex-specific differences revealed that male and female lady beetles are coated by the same blend of CHCs (Hemptinne et al. 1998). Hemptinne et al. (1998) suggest that lady beetles rely on behavior for discrimination between males and females. Moreover, generally weak ant aggression against elytra might mitigate differences in aggression between lady beetle species that occur under natural conditions (i.e. against living lady beetles).

Our chemical analyses of the lady beetle cues revealed a unique CHC profile for each lady beetle species. All species were significantly different from each other, with only few shared substances among all lady beetle species. The shared substances (e.g. $n$-C22, $n$-C23, $n$-C25, and $n$-C27) 
are commonly found in many insect species and, due to their high melting point, have been related to waterproofing rather than to recognition (Menzel et al. 2019). Notably, the species showed a remarkable chemical diversity even concerning the dominant substance classes: while $C$. septempunctata and $A$. bipunctata profiles were dominated by monomethyl alkanes, $H$. axyridis and $H$. variegata mostly possessed alkenes, and $P$. quatuordecimpunctata mostly contained alkadienes. All of these compounds have vastly different physical properties (Menzel et al. 2019). The adaptive value of these differences still remains to be found. Interestingly, the main compound in our $H$. axyridis samples, a C25-alkene, was not reported in conspecific samples from Japan (Magro et al. 2010a), which might be due to between-population differences in this species. Usually, CHC profiles are qualitatively quite invariant within a species (Kather and Martin 2012, Sprenger and Menzel 2020), which is why they are highly useful for chemotaxonomy, i.e. to distinguish closely related or cryptic species. So far, lady beetle CHCs have mainly been studies in the context of mating (Hemptinne et al. 1998; Legrand et al. 2019), as oviposition deterring pheromone in the tracks of the larvae (Hemptinne et al. 2001), but also the role of CHCs on lady beetle eggs for cannibalism and intraguild predation has been studied (Hemptinne et al. 2000). The species-specific chemical profiles of lady beetles also mean that there is likely no general chemical lady beetle cue (i.e. substances present on all aphidophagous lady beetles). Rather, ants have to recognize each species individually, be it by learning or by evolutionary adaptation. Cue dissimilarity between native and non-native predators as well as species-specific recognition cues are a prerequisite for predator-predator naïveté against invasive predators (Sih et al. 2010). Interestingly, we found no differences in the frequency of ant aggression nor in lady beetle reaction between H. axyridis and $H$. variegata. In our study, this species pair is also the most similar one concerning their CHC classes, which might be due to their close phylogenetic relatedness; Hippodamia and Harmonia seem to be sister genera (Magro et al. 2010b; Escalona et al. 2017). Thus, native ants might recognize the invasive $H$. axyridis as a Hippodamia-like lady beetle and behave accordingly. However, a larger species set would be required to formally link chemical cue similarity or phylogenetic relatedness with aggression strength.

\section{Conclusions}

Our behavioral experiments revealed differences in ant aggression and lady beetle reaction between ant and lady beetle species. In particular, L. niger showed more aggression towards lady beetles compared to M. rubra, and aggression of $L$. niger was more frequent towards most native lady beetle species compared to the invasive
$H$. axyridis. The frequency of this intraguild interference is influenced by the presence of chemical cues on the surface of lady beetles. CHC profiles of the lady beetles were species-specific and highly divergent, and we could not find any lady beetle-specific pattern or compound that would not occur in other insects as well (see e.g. Kather and Martin 2015; Sprenger and Menzel 2020). Moreover, secondary metabolites (e.g. defensive compounds; Haulotte et al. 2012) differ between lady beetle species. Therefore, the existence of general chemical lady beetle cues seems unlikely making it necessary for ants to recognize lady beetle species individually, although it is possible that they might lump chemically similar species.

Our aggression assays with L. niger thus provide support for the theoretical framework proposed by Sih et al. (2010) suggesting predator-naïveté against novel predators if interaction partners rely on species-specific cues. However, some native lady beetle species responded similarly to both ant species compared with the invasive $H$. axyridis, and also received relatively little ant aggression. This contradicts a simple native/non-native dichotomy. Note however, that $H$. axyridis is about as large as $C$. septempunctata, and both species have similarly high aphid consumption rates, compared to the other three species, which are smaller and less voracious (Ünlü et al. 2020; Bertleff et al. 2021). Therefore, when accounting for further variables like aphid consumption rate, the low aggression towards the invasive $H$. axyridis is conspicuous. Less frequent $L$. niger aggression and lady beetle reaction likely benefits the non-native lady beetle $H$. axyridis when competing with the equally voracious native $C$. septempunctata for ant-tended aphids and might ultimately contribute to its invasion success.

Supplementary Information The online version contains supplementary material available at https://doi.org/10.1007/s00049-021-00354-4.

Acknowledgements We would like to thank Carolin Gutwirth, Jördis F. Terlau, Jette Diekmann, and Denise Bertleff for their valuable help in the field and in the laboratory. We are grateful to the Julius-KühnInstitut (Braunschweig, Germany) for providing pea aphids. We thank the anonymous reviewers for helpful comments on previous versions of the manuscript.

Author contributions Conceptualization: RB, FM. Methodology: RB, LMJ, AGU, FM. Formal analysis and investigation: RB, LMJ, AGU. Writing—original draft preparation: RB, LMJ. Writing-review and editing: RB, LMJ, AGU, FM. Funding acquisition: RB. Resources: RB. Supervision: RB, FM.

Funding Open Access funding enabled and organized by Projekt DEAL. The study was funded by the Deutsche Forschungsgemeinschaft (DFG) under Grant No. BU3382/1-1 to RB. 
Availability of data and material All behavioral data as well as detailed information about identified substances are provided as supplementary material.

Code availability Standard applications of the open software R Development Core Team (2018) R: a language and environment for statistical computing, Version 3.5.2. R Foundation for Statistical Computing. http://www.R-project.org, Vienna, Austria.

\section{Declarations}

Conflict of interest The authors have no conflict of interest to declare.

Consent for publication Contributor-owned work.

Open Access This article is licensed under a Creative Commons Attribution 4.0 International License, which permits use, sharing, adaptation, distribution and reproduction in any medium or format, as long as you give appropriate credit to the original author(s) and the source, provide a link to the Creative Commons licence, and indicate if changes were made. The images or other third party material in this article are included in the article's Creative Commons licence, unless indicated otherwise in a credit line to the material. If material is not included in the article's Creative Commons licence and your intended use is not permitted by statutory regulation or exceeds the permitted use, you will need to obtain permission directly from the copyright holder. To view a copy of this licence, visit http://creativecommons.org/licenses/by/4.0/.

\section{References}

Alyokhin A, Sewell G (2004) Changes in a lady beetle community following the establishment of three alien species. Biol Invasions 6:463-471

Arim M, Marquet PA (2004) Intraguild predation: a widespread interaction related to species biology. Ecol Lett 7:557-564

Babendreier D (2007) Pros and cons of biological control. In: Nentwig W (ed) Biological invasions. Springer, Berlin Heidelberg

Bax N, Williamson A, Aguero M et al (2003) Marine invasive alien species: a threat to global biodiversity. Mar Policy 27:313-323

Bertleff D, Diekmann J, Brand S et al (2021) Predation and avoidance behavior in aphid-ladybird interactions of native and invasive ladybirds in Europe. Ecol Entomol 46:41-47

Binz H, Foitzik S, Staab F et al (2014) The chemistry of competition: exploitation of heterospecific cues depends on the dominance rank in the community. Anim Behav 94:45-53

Blackburn TM, Pyšek P, Bacher S et al (2011) A proposed unified framework for biological invasions. Trends Ecol Evol 26:333-339

Bos N, Dreier S, Jørgensen CG et al (2012) Learning and perceptual similarity among cuticular hydrocarbons in ants. J Insect Physiol 58:138-146

Brown PMJ, Adriaens T, Bathon $\mathrm{H}$ et al (2007) Harmonia axyridis in Europe: spread and distribution of a non-native coccinellid. In: Roy HE, Wajnberg E (eds) From biological control to invasion: the ladybird Harmonia axyridis as a model species. Springer, Dordrecht

Brown PMJ, Frost R, Doberski J et al (2011) Decline in native ladybirds in response to the arrival of Harmonia axyridis, early evidence from England. Ecol Entomol 36:231-240

Carthey AJ, Banks PB (2014) Naïveté in novel ecological interactions: lessons from theory and experimental evidence. Biol Rev 89:932-949
Colautti RI, Ricciardi A, Grigorovich IA et al (2004) Is invasion success explained by the enemy release hypothesis? Ecol Lett 7:721-733

Cox JG, Lima SL (2006) Naiveté and an aquatic-terrestrial dichotomy in the effects of introduced predators. Trends Ecol Evol 21:674-680

Dupuy F, Sandoz J-C, Giurfa M et al (2006) Individual olfactory learning in Camponotus ants. Anim Behav 72:1081-1091

Elliott N, Kieckhefer R, Kauffman W (1996) Effects of an invading coccinellid on native coccinellids in an agricultural landscape. Oecologia 105:537-544

Escalona HE, Zwick A, Li HS et al (2017) Molecular phylogeny reveals food plasticity in the evolution of true ladybird beetles (Coleoptera: Coccinellidae: Coccinellini). BMC Evol Biol 17:151

Finlayson CJ, Alyokhin AV, Porter EW (2009) Interactions of native and non-native lady beetle species (Coleoptera: Coccinellidae) with aphid-tending ants in laboratory arenas. Environ Entomol 38:846-855

Flatt T, Weisser WW (2000) The effects of mutualistic ants on aphid life history traits. Ecology 81:3522-3529

Foitzik S, Sturm H, Pusch K et al (2007) Nestmate recognition and intraspecific chemical and genetic variation in Temnothorax ants. Anim Behav 73:999-1007

Geiselhardt SF, Geiselhardt S, Peschke K (2011) Congruence of epicuticular hydrocarbons and tarsal secretions as a principle in beetles. Chemoecology 21:181-186

Greene MJ, Gordon DM (2003) Social insects: cuticular hydrocarbons inform task decisions. Nature 423:32

Harmon JP, Stephens E, Losey J (2006) The decline of native coccinellids (Coleoptera: Coccinellidae) in the United States and Canada. In: New TR (ed) Beetle conservation. Springer, Dordrecht

Harrison XA (2014) Using observation-level random effects to model overdispersion in count data in ecology and evolution. PeerJ 2:e616

Haulotte E, Laurent P, Braekman J-C (2012) Biosynthesis of defensive Coccinellidae alkaloids: incorporation of fatty acids in Adaline, Coccinelline, and Harmonine. Eur J Org Chem 2012:1907-1912

Hayes KR, Barry SC (2008) Are there any consistent predictors of invasion success? Biol Invasions 10:483-506

Hemptinne J-L, Lognay G, Dixon AFG (1998) Mate recognition in the two-spot ladybird beetle, Adalia bipunctata: role of chemical and behavioural cues. J Insect Physiol 44:1163-1171

Hemptinne J-L, Lognay G, Gauthier C et al (2000) Role of surface chemical signals in egg cannibalism and intraguild predation in ladybirds (Coleoptera: Coccinellidae). Chemoecology 10:123-128

Hemptinne J-L, Lognay G, Doumbia M et al (2001) Chemical nature and persistence of the oviposition deterring pheromone in the tracks of the larvae of the two spot ladybird, Adalia bipunctata (Coleoptera: Coccinellidae). Chemoecology 11:43-47

Herbert JJ, Horn DJ (2008) Effect of ant attendance by Monomorium minimum (Buckley) (Hymenoptera: Formicidae) on predation and parasitism of the soybean aphid Aphis glycines Matsumura (Memiptera: Ahididae). Environ Entomol 37:1258-1263

Howard RW, Blomquist GJ (2005) Ecological, behavioral, and biochemical aspects of insect hydrocarbons. Annu Rev Entomol 50:371-393

Hufbauer RA, Torchin ME (2008) Integrating ecological and evolutionary theory of biological invasions. In: Nentwig W (ed) Biological invasions. Springer, Berlin Heidelberg

Hulme PE, Bacher S, Kenis M et al (2008) Grasping at the routes of biological invasions: a framework for integrating pathways into policy. J Appl Ecol 45:403-414

Kajita Y, Obrycki JJ, Sloggett JJ et al (2010) Intraspecific alkaloid variation in ladybird eggs and its effects on con-and hetero-specific intraguild predators. Oecologia 163:313-322 
Kajita Y, Obrycki JJ, Sloggett JJ et al (2014) Do defensive chemicals facilitate intraguild predation and influence invasion success in ladybird beetles? J Chem Ecol 40:1212-1219

Kather R, Martin SJ (2012) Cuticular hydrocarbon profiles as a taxonomic tool: advantages, limitations and technical aspects. Physiol Entomol 37:25-32

Kather R, Martin SJ (2015) Evolution of cuticular hydrocarbons in the hymenoptera: a meta-analysis. J Chem Ecol 41:871-883

Keane RM, Crawley MJ (2002) Exotic plant invasions and the enemy release hypothesis. Trends Ecol Evol 17:164-170

Kenis M, Auger-Rozenberg M-A, Roques A et al (2009) Ecological effects of invasive alien insects. Biol Invasions 11:21-45

Koch RL (2003) The multicolored Asian lady beetle, Harmonia axyridis: A review of its biology, uses in biological control, and nontarget impacts. J Insect Sci 3:1-16

Lang C, Menzel F (2011) Lasius niger ants discriminate aphids based on their cuticular hydrocarbons. Anim Behav 82:1245-1254

Legrand P, Vanderplanck M, Lorge S et al (2019) Cuticular hydrocarbon composition does not allow Harmonia axyridis males to identify the mating status of sexual partners. Entomol Gen 38:211-224

Lima SL, Dill LM (1990) Behavioral decisions made under the risk of predation: a review and prospectus. Can J Zool 68:619-640

Lodge DM (1993) Biological invasions: lessons for ecology. Trends Ecol Evol 8:133-137

Mack RN, Simberloff D, Mark Lonsdale W et al (2000) Biotic invasions: causes, epidemiology, global consequences, and control. Ecol Appl 10:689-710

Magro A, Ducamp C, Ramon-Portugal F et al (2010a) Oviposition deterring infochemicals in ladybirds: the role of phylogeny. Evol Ecol 24:251-271

Magro A, Lecompte E, Magne F et al (2010b) Phylogeny of ladybirds (Coleoptera: Coccinellidae): are the subfamilies monophyletic? Mol Phylogenet Evol 54:833-848

Marples NM (1993) Is the alkaloid in 2spot ladybirds (Adalia bipunctata) a defence against ant predation? Chemoecology 4:29-32

Menzel F, Schmitt T (2012) Tolerance requires the right smell: first evidence for interspecific selection on chemical recognition cues. Evolution 66:896-904

Menzel F, Schmitt T, Blüthgen N (2009) Intraspecific nestmate recognition in two parabiotic ant species: acquired recognition cues and low inter-colony discrimination. Insect Soc 56:251-260

Menzel F, Blaimer BB, Schmitt T (2017) How do cuticular hydrocarbons evolve? Physiological constraints and climatic and biotic selection pressures act on a complex functional trait. P R Soc Lond B Biol 284:20161727

Menzel F, Morsbach S, Martens JH et al (2019) Communication versus waterproofing: the physics of insect cuticular hydrocarbons. J Exp Biol 222:jeb210807. https://doi.org/10.1242/jeb.210807

Mestre L, Bucher R, Entling MH (2014) Trait-mediated effects between predators: ant chemical cues induce spider dispersal. J Zool 293:119-125

Monnin T (2006) Chemical recognition of reproductive status in social insects. Ann Zool Fenn 43:515-530

Mooney HA, Cleland EE (2001) The evolutionary impact of invasive species. P Natl Acad Sci USA 98:5446-5451

Oksanen J, Blanchet FG, Kindt MFR et al (2013) Vegan: community ecology package. R-package version 2.0.7. https://cran.r-project. org

Parker IM, Simberloff D, Lonsdale WM et al (1999) Impact: toward a framework for understanding the ecological effects of invaders. Biol Invasions 1:3-19

Pell JK, Baverstock J, Roy HE et al (2008) Intraguild predation involving Harmonia axyridis: a review of current knowledge and future perspectives. In: Roy HE, Wajnberg E (eds) From biological bontrol to invasion: the ladybird Harmonia axyridis as a model species. Springer, Dordrecht

Penn HJ, Athey KJ (2020) Ants increase cloverworm herbivory via nonconsumptive pathways. Fla Entomol 103:160-167

Pettersson J (2012) Coccinellids and semiochemicals. In: Hodek I, van Emden HE, Honek A (eds) Ecology and behavior of the ladybird beetles (Coccinellidae). Blackwell Publishing Ltd

Polis GA, Meyers CA, Holt RD (1989) The ecology and evolution of intraguild predation: potential competitors that eat each other. Annu Rev Ecol Syst 20:297-330

R Development Core Team (2018) R: a language and environment for statistical computing, Version 3.5.2. R Foundation for Statistical Computing. http://www.R-project.org, Vienna, Austria

Roy HE, Wajnberg E (2008) From biological control to invasion: the ladybird Harmonia axyridis as a model species. Biocontrol 53:1-4

Roy HE, Bhatkar T, Isaac NJ et al (2012) Invasive alien predator causes rapid declines of native European ladybirds. Divers Distrib 18:717-725

Sanders D, Schaefer M, Platner C et al (2011) Intraguild interactions among generalist predator functional groups drive impact on herbivore and decomposer prey. Oikos 120:418-426

Seifert B (2007) Die Ameisen Mittel- und Nordeuropas. Lutra Verlag, Tauer

Sih A, Bolnick DI, Luttbeg B et al (2010) Predator-prey naïveté, antipredator behavior, and the ecology of predator invasions. Oikos 119:610-621

Sloggett JJ, Majerus MEN (2000) Aphid-mediated coexistence of ladybirds (Coleoptera: Coccinellidae) and the wood ant Formica rufa: seasonal effects, interspecific variability and the evolution of coccinellid myrmecophile. Oikos 89:345-359

Sloggett JJ, Wood RA, Majerus MEN (1998) Adaptions of Coccinella magnifica Redtenbacher, a myrmecophilous Coccinellid, to aggression by wood ants (Formica rufa Group). I. Adult behavioral adaptation, its ecological context and evolution. J Insect Behav 11:889-904

Sprenger PP, Menzel F (2020) Cuticular hydrocarbons in ants (Hymenoptera: Formicidae) and other insects: how and why they differ among individuals, colonies, and species. Myrmecol News 30:1-26

Stadler B, Dixon AF (2005) Ecology and evolution of aphid-ant interactions. Annu Rev Ecol Evol Syst 36:345-372

Steiner FM, Schlick-Steiner BC, Moder K et al (2007) Abandoning aggression but maintaining self-nonself discrimination as a first stage in ant supercolony formation. Curr Biol 17:1903-1907

Ünlü AG, Terlau JF, Bucher R (2020) Predation and avoidance behavior of the pea aphid Acyrthosiphon pisum confronted with native and invasive lady beetles in Europe. Biol Invasions 22:1647-1656

Vance-Chalcraft HD, Soluk DA (2005) Estimating the prevalence and strength of non-independent predator effects. Oecologia 146:452-460

Vilcinskas A, Stoecker K, Schmidtberg H et al (2013) Invasive harlequin ladybird carries biological weapons against native competitors. Science 340:862-863

Völkl W, Woodring J, Fischer M et al (1999) Ant-aphid mutualism: the impact of honeydew production and honeydew sugary composition on ant preference. Oecologia 188:483-491

Way MJ (1963) Mutualism between ants and honeydew-producing Homoptera. Annu Rev Entomol 8:307-344

Wüst M, Menzel F (2017) I smell where you walked-how chemical cues influence movement decisions in ants. Oikos 126:149-160 